\title{
Evaluation of Rehabilitation Services Provided to Drug Addicts in District Peshawar
}

\author{
Ramsha Hamid, Naveeda Sarwar, Adnan sarwar, Saira Gul, Saman, Hassnain Masood \\ ${ }^{1,6}$ Lecturer Community Medicine, Pak International Medical College, Peshawara. \\ ${ }^{2}$ Psychologist Community Medicine Pak International Medical College, Peshawar \\ ${ }^{3}$ Assistant Professor, pathology Pak International Medical College, Peshawar \\ ${ }^{4}$ Psychologist, HoD,shukat Khanam Memorial Hospital, Peshawar \\ ${ }^{5}$ Senior lecturer, pathology Pak international medical college, Peshawar
}

\begin{tabular}{lll}
\multicolumn{2}{l}{ Article Information } \\
Received & $:$ & 25 Sep 2020 \\
Revised & $:$ & 02 Oct 2020 \\
Accepted & $:$ & 10 Oct 2020 \\
Published & $:$ & 25 Oct 2020
\end{tabular}

Abstract- Rehabilitation is an integrated program of interventions that empower individuals with disabilities and chronic health conditions to achieve "personally fulfilling, socially meaningful, and functionally effective interaction" in their daily contexts. The Objectives are to assessing the rehabilitation services provided to the drug addicts in Peshawar and to assess the role of government sector rehabilitation centers and the private sector rehabilitation centers in reducing the sufferings of the drug addicts. Methodology is A cross sectional analytical study was conducted in 4 rehabilitation centers of Peshawar city i.e. KTH, LRH, DWF Hayatabad and DWF Shahibala, selected by convenient sampling technique. A closed ended questionnaire was planned with a checklist of services provided in the drug rehabilitation centers. This was filled by the staff members of the rehabilitation centers. Also 131 drug addicts who were present in rehabilitation centers on the day of interview and were willing to participate in the study were included in the study population. Data was analyzed through Spss v.22 and different statistical test were applied. Results is Drug addiction was found to be 54\% among the younger age group of 21-30 years. A significant $(\mathrm{p}=0.029)$ association was found between marital status and relapse of drug addiction. History of imprisonment had a significant relationship $(\mathrm{p}=0.003)$ with relapse. Another significant association $(\mathrm{p}=0.01)$ was found to exist between peer pressure and relapse. The results of the study explain that the services available for rehabilitation of drug addicts are not sufficient and the relapse rate more in public sector rehabilitation centers and the possible risk factors for relapse are peer influence, marital status and a history of imprisonment. Conclusion of this research On the basis of the results and statistical analysis of our research study it can be concluded that the services available for the rehabilitation of drug addicts in Peshawar are not sufficient. The number of drug rehabilitation centers and the treatment slots available in those centers are few in number. Also most of the drug rehabilitation centers are

Corresponding Author: providing the inpatient type of treatment setting which makes it impossible for a large number of drug addicts to get the benefits of rehabilitation programs. The rehabilitation services are not

Naveeda Sarwar free of cost and a large number of drug addicts cannot afford the service charges as disallowance mechanism is not effective in the centers.

Email:

naveedasarwar6@gmail.com

Keywords: cross-sectional, dost welfare foundation, ,drug addicts, LRH, rehabilitation

Copyright (C) 2020: Naveeda Sarwar. This is an open access distribution, and reproduction in any medium, provided Access article distributed under the Creative Commons Attribution License the original work is properly cited License, which permits unrestricted use.

Citation: Ramsha Hamid, Naveeda Sarwar, Adnan sarwar, Saira Gul, Saman, Hassnain Masood. "Evaluation of Rehabilitation Services Provided to Drug Addicts in District Peshawar, "Journal of Science, Computing and Engineering Research, 1(4), 73-78, September - October 2020.

\section{INTRODUCTION}

Drug addiction is a complex illness characterized by intense and, at times, uncontrollable drug craving, along with compulsive drug seeking and use that persist even in the face of devastating consequences. Addiction is a brain disease that affects multiple brain circuits, including those involved in reward and motivation, learning and memory, and inhibitory control over behavior. [1]. According to United Nations Office on Drugs and Crime, Pakistan has 6.7 million drug users. More than 4 million of these are addicts, amongst the highest number for any country in the world. Most of these drugs come from Afghanistan, the country that is responsible for at least $75 \%$ of the world's heroin.[2].Drug rehabilitation (often drug rehab or just rehab) is a term for the processes of medical or psychotherapeutic treatment, for dependency on psychoactive substances such as alcohol, prescription drugs, and street drugs such as cocaine, heroin or amphetamines. The general intent is to enable the patient to cease substance 
abuse, in order to avoid the psychological, legal, financial, social, and physical consequences that can be caused, especially by extreme abuse(3). When key informants were asked whether there were drug treatment services in their locality, around one-third of informants in Punjab, Balochistan, and Khyber Pakhtunkhwa reported availability of local drug treatment services. In Sindh, only $17 \%$ of key informants cited a drop-in center in their area. No key informants in Pakistan-administered Kashmir were aware of services for drug users in the region. Findings from the problem drug user assessment also revealed insufficient treatment service capacity and coverage, with less than half of all opiate users aware of an operating drug treatment centre in their area. More than three-quarters of regular opiate users across all regions of Pakistan identified the need for drug treatment centers as 'urgent' 4 . The rationale of the study is that drug addiction is a rising health problem and those people who are addicted to drugs suffer a lot of social and health problems. The addicts pose a problem to their families and it is need of the hour that serious steps should be taken to reduce drug addiction as well as for the complete rehabilitation of the already addicted ones. This topic was selected because very little research has been done on the facilities that are available to the drug addicts for their rehabilitation as far as Peshawar city is concerned. This problem calls for more and more meticulous research studies.

\section{METHODOLOGY}

An analytical descriptive cross-sectional study was carried out on April 2019 to June 2019 to assess the services provided for the rehabilitation of drug addicts. The study was conducted on drug rehabilitation centers in Peshawar, containing of Khyber Teaching Hospital, Lady Reading Hospital, Dost Welfare Foundation Hayatabad, and Dost Welfare Foundation Shahibala. The study population was drug addicts admitted in various drug rehabilitation institutes of Peshawar. The respondents of the study were 131 drug addicts who were getting treatment in four rehabilitation centers of Peshawar. Convenient sampling technique was used. The questionnaire consists of demographic data i-e institution, gender and residence while the rehabilitation part of questionnaire were included i-e For the assessment of rehabilitation services the following variables were studied ;Level I care - outpatient : outreach, drop in etc. Which is provided to persons affected by drug use and not in contact with formal treatment, Level II carepartial hospitalization: treatment in a non-residential setting where the patient is made to stay for several hours daily, Level III care-residential: residential structured emphasis, includes care typically provided in residential settings. It is given to patients whose living place is toxic or unsafe, interpersonal relations abusive, long histories of treatment, law enforcement problems and poor job or educational performance, Level IV care-hospital: inpatient care where emphasis is given on general and specialized medical care. Delivered to individuals who need deriving from substance abuse disorders with moderate or severe mental health and medical complications, Level V care- Crisis intervention: immediate care services that must be available to patient when there is risk to patient's life due to acute complications of drug abuse? The collected data was analyzed by using a computer program, i.e. Statistical Package for Social Sciences (SPSS, 20 version). On the basis of data entered into the program frequency and percentages were drawn. Chi-square test was applied for qualitative data and for finding association between dependent and independent variables.

\section{RESULTS}

Location of the responding rehabilitation centers $3(75 \%)$ of the responding rehabilitation centers of Peshawar have rural location whereas $1(25 \%)$ of the respondents have urban location. $2(50 \%)$ of the treatment programs are governed by government while $2(50 \%)$ of the centers are private sector institutes. $100 \%$ of the respondents were the male drug addicts and admitted in various rehabilitation centers and there were no females. The figure also explain the distribution on the basis of religion showing that $91.6 \%$ of the respondents were Muslims while $8.0 \%$ of the responding drug addicts were from other religions.

Table I. Level I care by rehabilitation centers in Peshawar

\begin{tabular}{lllll}
\multicolumn{5}{c}{ Type of treatment programmed } \\
\hline S.no & $\begin{array}{l}\text { Provision of } \\
\text { level I care }\end{array}$ & Pubic & $\begin{array}{l}\text { Private } \\
\text { Non-profit }\end{array}$ & Total \\
\hline I & Yes & 0 & 1 & 1 \\
ii & No & 2 & 1 & 3 \\
iii & Total & 2 & 2 & 4 \\
\hline
\end{tabular}

Table II. Availability of Level II care in Rehabilitation centers in Peshawar

Type of treatment programed

\begin{tabular}{lllll}
\hline S.no & $\begin{array}{l}\text { Provision of } \\
\text { level II care }\end{array}$ & public & $\begin{array}{l}\text { Private } \\
\text { non-profit }\end{array}$ & Total \\
\hline I & Yes & 0 & 1 & 1 \\
II & No & 2 & 1 & 3 \\
III & Total & 2 & 2 & 4 \\
\hline
\end{tabular}

Table III. Rehabilitation centers in Peshawar giving level III care

Type of treatment programed

\begin{tabular}{cllll}
\hline S.no. & $\begin{array}{l}\text { Provision of } \\
\text { level III care }\end{array}$ & Public & $\begin{array}{l}\text { Private } \\
\text { Non- } \\
\text { profit }\end{array}$ & Total \\
\hline I & Yes & 0 & 2 & 2 \\
II & No & 2 & 0 & 2
\end{tabular}


III Total 2 2 4

Table IV. The provision of level IV treatment facility in rehabilitation centers of Peshawar

Type of treatment programed

\begin{tabular}{lllll}
\hline S.no & $\begin{array}{l}\text { Provision of } \\
\text { level IV care }\end{array}$ & Public & Private & Total \\
\hline I & Yes & 2 & 1 & 3 \\
II & No & 0 & 1 & 1 \\
III & Total & 2 & 2 & 4 \\
\hline
\end{tabular}

IV. DISCUSSION

Rehabilitation centers deliver level $\mathrm{V}$ care (crisis intervention) to their clients while 2 centers do not have this establishment. Furthermore from this table we conclude that Dost Welfare Foundation Hayatabad and Khyber Teaching Hospital confer Level V care and are a step ahead in their services as crisis intervention is necessary to save patient's life. It states that none of the centers has its own resources for maintenance that 3 rehabilitation centers are aided by the government/public and 1center is not supported by the government. The results reflect that private sector rehabilitation centers are jacked up by cooperation from international organizations. Whereas the government drug rehabilitation centers are not getting international boost. the various settings in which detoxification services are provided in the drug rehabilitation centers of Peshawar. The table shows that detoxification services are provided by all public and private sector drug rehabilitation centers. Although the settings are different. The service is conferred by both the public and private sector centers in withdrawal and management whereas only the private sector centers deliver it in the residential setting. For short-term nonresidential patients no detoxification services are available.

Data analysis of our research project show that outpatient treatment facility for rehabilitation of drug addicts is provided by only one drug rehabilitation center in center in Peshawar. From this we infer that rehabilitation services for drug addiction are not sufficient because outpatient services are important for those addicts who are engaged in such an employment where they cannot manage to get admission into a full term residential treatment program. Similar studies were found in a report of NIDA (2010)5 which states that Outpatient treatment varies in the types and intensity of services offered. Such treatment costs less than residential or inpatient treatment and often is more suitable for people with jobs or extensive social supports. In many outpatient programs, group counseling can be a major component. Some outpatient programs are also designed to treat patients with medical or other mental health problems in addition to their drug disorders. This explains that outpatient treatment service plays an important role in the rehabilitation of drug addicts since we have only one rehabilitation center providing this facility which can point towards a possible reason for insufficient rehabilitation services and possible rise in relapse of drug addiction.

The results of our study also showed that the government drug rehabilitation centers of Peshawar are not providing the partial hospitalization facility whereas only one private sector rehabilitation center is delivering this type of facility of drug rehabilitation. Partial hospitalization focuses on the overall treatment of an individual, and is intended to avert or reduce in-patient hospitalization. Studies of Dr. Albert Moll (2011) 6 suggests that some patients would be unable to be away from their work or from their families and that these programs would reduce the cost of long term care. Hospitals are using partial hospitalization to handle acutely ill patients who are able to better understand their illness, become adjusted to medication regime and set recovery goals that enable them to function effectively as recovered individuals in the society. The results of our research our explains that legal assistance to drug addicts having some history of imprisonment for offence of drug use any other crime is given in three of the rehabilitation centers out of which one center is a government sector rehabilitation center. This proves that the rehabilitation centers of Peshawar are providing an important service to the reduce the misery of the addicts. This could be helpful in reducing the frequency of relapse of addiction because the present study reveals that waiver mechanism for drug addicts who are not able to pay for the treatment services does not exist in two of the rehabilitation centers. This explains a possible cause of treatment failure in many addicts because if an addict is not able to pay the charges he will not get admission in a rehabilitation center or will have to leave the treatment course in the middle. This could be advocated by study of Shah SA Altaf (2013) 7 that not all the treatment is free of charge. In a country where almost quarter of a population is estimated to be living on less than US\$ 1.25 a day the barriers preventing access to treatments are exceptionally strong.[8]

The results of our survey also reveals that admission into treatment facility is provided to all drug addicts irrespective of the age, sex, social status, psychiatric conditions and legal status of the person. This points towards a good omen that doors of rehabilitation are open for all classes of the society. From our study we also infer that detoxification a major treatment modality in drug addiction is available but this is not available to all the addicts in short term residential treatment. This leads us to the shortcomings in the services available for the rehabilitation of drug addicts and an increase rate of relapse. This is in accordance with a report of UNODCCP (2000)9 which states that there is no definite criteria for selecting a person for outpatient detoxification. The success of this service is low; only $35 \%$ of patients ever complete the detoxification process. Currently, in patient detoxification for a period of ten days is the only other intervention offered by the Centres. In patient detoxification 
consists of symptomatic treatment of withdrawal symptoms using non-narcotic analgesics such as Mefenemic acid or Brufen, hypnotics such as Mogadon or tranquillizers such as Ativan, along with other supportive therapy. The results of our study also show that psychosocial therapy is delivered in all the drug rehabilitation centers of Peshawar under study. It shows that a major protocol of the treatment is followed for the rehabilitation of drug addicts. Psychosocial services are provided in many countries and it is considered as an important treatment/relapse prevention therapy. UNODC report (2003) 10 states that Community or day programed offer a programed of psychotherapy or general counselling based on a care plan. The programed is usually individually configured to meet the needs of each participant using a case management approach. In many countries, most drug abuse counsellors use a client-centered, cognitive behavioral and motivational framework, and offer treatment that varies in duration from a brief intervention lasting from one to three sessions to a formal structured programed lasting several months. Riffat Sadiq (2013) 11 states that Cognitivebehavior therapy is effective in relapse prevention. Its helps to identify high risk factors of relapse, decrease sense of helplessness in front of Problematic situation and enhance self-control in recovering addicts. Techniques included in cognitive-behavior therapy deal with craving, relapse and other problems. It can be used during rehabilitation and aftercare services. It appeared to be an effective tool to treat variety of drug abuse problems.

Monitoring of client's abstinence is very important regarding the rehabilitation of drug addiction because if the abstinence is not monitored an addicts can easily get back to use of addictive drugs. The results of our survey show that out of four rehabilitation centers monitoring of client's abstinence is done in three rehabilitation centers of which one is a government sector rehabilitation center. The importance of monitoring of drug abstinence is shown by a statement in report of National Institute of Drug Abuse (2004) 12 which states that possible drug use during treatment must be monitored continuously. The objective monitoring of a patient's drug and alcohol use during treatment can help the patient withstand urges to use drugs.

The results of our survey explains that vocational training to the drug addicts when they are admitted for rehabilitation is given in two of the private rehabilitation centers. The government sector institutes are not providing any guidance in this regard. This can explain a possible reason for risk of increased relapse in government sector institutes because they are not providing any vocational training so that the rehabilitating drug addicts can earn a suitable livelihood. The importance of vocational training is explained in The Report of the working group on drugs rehabilitation [12] recommends that measures to improve the employability of current, former and recovering drug users should form a key part of rehabilitation care plans, with the overall aim 'to maximize the quality of life, reengagement in independent living and employability of the recovering problem drug user, in line with their aspirations.
This points to the fact that the services provided for the rehabilitation of drug addicts cannot meet the international standards and are inadequate.

From the results of our research project we also infer that individualized drug counselling is given to the drug addicts in the rehabilitation centers of Peshawar. Individualized drug counselling is very important in prevention and rehabilitation of drug counselling the significance of which can be demonstrated by a report of SAMSHA (2010) which states that Individualized drug counseling not only focuses on reducing or stopping illicit drug or alcohol use; it also addresses related areas of impaired functioning - such as employment status, illegal activity, and family/social relations-as well as the content and structure of the patient's recovery program. Through its emphasis on shortterm behavioral goals, individualized counseling helps the patient develop coping strategies and tools to abstain from drug use and maintain abstinence. The addiction counselor encourages 12-step participation (at least one or two times per week) and makes referrals for needed supplemental medical, psychiatric, employment, and other services. This unveils the services supplied for the rehabilitation of drug addicts that an important milestone of rehabilitation is prove. The research study also shows that during rehabilitation in a drug rehabilitation center a drug addict is screened for HIV and hepatitis. This facility is available in all the drug rehabilitation centers of Peshawar. This leads us to a point that during the course of rehabilitation care is taken to check the general health of the addicts as well, so that after release they can live a normal healthy life. This is in accordance with international standards, a repot Treatment programs should provide assessment for HIV/AIDS, hepatitis B and C, tuberculosis and other infectious diseases and counseling to help patients modify or change behaviors that place themselves or others at risk of infection. Counseling can help patients avoid high-risk behavior. Counseling also can help people who are already infected manage their illness? Another objective of the research was to find out the rate and risk factors for relapse of drug addiction. The analysis of our data showed that about $41 \%$ of the sample drug addicts belonged to age group 21-30 years. Similar results were found in a report by UNODC in 2010 which states that an examination of social and demographic factors revealed that $71.5 \%$ of the drug abusers were less than 35 years of age. Prevalence of addiction in young age is most probably due to the fact that in the young age a person is easily influenced by his friends or TV adds etc. a person in young age lives in the world of fantasies and thinks that reality is not much different from what he thinks. Therefore an individual can easily become victim of drug abuse.

Analysis of our data also shows that drug addiction is commonly found in males and the percentage of addiction is zero percent in females. However this result is not in accordance with UNODC (2010) report on female drug users in Pakistan which states that unlike male drug users who congregate and use drugs with other drug users, drug

Page 76 
use is a discreet, hidden and more of an individual activity for female drug users. There is no doubt that women experience higher levels of stigma associated with drug use compared to that experienced by men. The results we found are due to the reason that drug addiction among females is considered a taboo and mostly females addicted to drugs are not given access to drug rehabilitation centers. We also found out that drug abuse is more common amongst temporary residents of Peshawar.

Unmarried young addicts are an easy victim of drug addiction in whom the percentage of drug addiction was $66.4 \%$. Drug addiction is common amongst the unmarried because they don't have the burden of taking care of a family and therefore whatever they earn they use it in fulfilling their craving for drugs. Similar findings were shown by Analysis of the employment and educational status of most of the addicts proved that tendency towards drug addiction is common in laborers (35.1\%). Among occupational categories, the frequency of drug abuse was highest $50.8 \%$ for those in skilled and unskilled labour categories, followed by sales $16.8 \%$, agriculture $7.4 \%$ and students also $7.4 \%$ [16] and illiterate (45.9\%).

As far as the risk factors for relapse of drug addiction are concerned a significant association $(p<0.03)$ was found between marital status and relapse of drug addiction. Similar results were found in a report by Gomal general of medicine, (2004) which stated that marital bondages are more stressful than being supportive. A previous addict having problems with his wife may force him to plunge into world of drugs. Our results also showed a significant relationship $(\mathrm{p}=0.000)$ between leaving the treatment course in the middle and the relapse of drug addiction. $14.5 \%$ of the addicts who left the course in the middle said that they were not able to afford the charges of the rehabilitation services. In accordance to this result states that not all the treatment is free of charge. In a country where almost quarter of a population is estimated to be living on less than US\$ 1.25 a day the barriers preventing access to treatments are exceptionally strong. A significant association $(p=0.01)$ was found to exist between peer influence and tendency of a former addict towards drug addiction. This result is supported by a report of cbsnews.com (2009) states that many young people say that being encouraged by friends to use marijuana, alcohol or other drugs caused them to start on their drug career. When one is trying to recover from a past addiction, the same kinds of pressures exist. Just because a person gets sober doesn't mean that he automatically knows how to avoid every temptation. The results of our research project showed a non-significant $(\mathrm{p}<0.744)$ affiliation between bereavement in family and tendency of relapse in a previous addict. This indicates that bereavements in family is not a risk factor for relapse of drug addiction, however this result is in contrast to findings of Alan Leshner (2009) who stated that most relapses among addicts occur addicts occur in a 'negative mood state' and findings by Janet Frishein (2010) who states that, other things are impacting their (addicts) lives that lead them back to using drugs, such as death of someone close. The findings of this sample are non-significant most probably due to a small sample size. A significant relationship ( $p=0.003$ ) was found between history of imprisonment of addicts and the relapse. Similar results were found by Yuki Maehira (2011) which states that Despite the high prevalence of substance use disorders among individuals in prison, our results suggest that former inmates with a history of drug use disorders and criminal drug charges are often released into environments with significant social and economic challenges, little structure, and ubiquitous drug activity. These challenges makes it difficult for former inmates with drug use disorders to remain abstinent from drugs and alcohol.

\section{CONCLUSION}

On the basis of the results and statistical analysis of our research study it can be concluded that the services available for the rehabilitation of drug addicts in Peshawar are not sufficient. The number of drug rehabilitation centers and the treatment slots available in those centers are few in number. Also most of the drug rehabilitation centers are providing the inpatient type of treatment setting which makes it impossible for a large number of drug addicts to get the benefits of rehabilitation programs. The rehabilitation services are not free of cost and a large number of drug addicts cannot afford the service charges as waiver mechanism is not effective in the centers. Lack of vocational training in the government sector drug rehabilitation centers in most of the cases leads to treatment failure and a high incidence of relapse.

\section{REFERENCES}

[1] Substance Abuse and Mental Health Services Administration, SAMSHA, (2009).

[2] Al Jazeera, 18 March 2015. Drugged up Pakistan

[3] www.wikipedia.com visited on 14.3.2015

[4] Report of National Institute on Drug Abuse NIDA, 2012.

[5] Maehle AH. 'God's Ethicist': Albert Moll and His Medical Ethics in Theory and Practice. Medical history. 2012 Apr; 56(2):217-36.

[6] Lipska KJ, Yao X, Herrin J, McCoy RG, Ross JS, Steinman MA, Inzucchi SE, Gill TM, Krumholz HM, Shah ND. Trends in drug utilization, glycemic control, and rates of severe hypoglycemia, 2006-2013. Diabetes care. 2017 Apr 1; 40(4):46875.

[7] United Nations Office on Drugs and Crime (UNODC). Protocol to prevent, suppress, and punish trafficking in persons, especially women and children. S. TREATY DOC NO. 108-16 (2004), 2237 UNTS 319. 2000.

[8] Sadiq, R. (2019). Helping Families of Drug Abusers.

[9] Damani S, Fulton S. Collaborating and delivering literature search results to clinical teams using Web 2.0 tools. Medical reference services quarterly. $2010 \mathrm{Jul} 28 ; 29(3): 207-17$.

[10] Baker D, McArthur T. The value of the" too big to fail" big bank subsidy. Washington, DC: Center for Economic and Policy Research; 2009 Sep.

[11] Andrews N, Burris JE, Cech TR, Coller BS, Crowley WF, Gallin EK, Kelner KL, Kirch DG, Leshner AI, Morris CD, Nguyen FT. Translational careers. Science. 2009 May 15; 324(5929):855. 
[12] Pemba CM, Kurosaki Y, Yoshikawa R, Oloniniyi OK, Urata S, Sueyoshi M, Zadeh VR, Nwafor I, Iroezindu MO, Ajayi NA, Chukwubike CM. Development of an RT-LAMP assay for the detection of Lassa viruses in southeast and south-central Nigeria. Journal of virological methods. 2019 Jul 1; 269:30-7. 